\title{
Effects of Stocking Density on the Blind-side Hypermelanosis of Cultured Olive Flounder Paralichthys olivaceus
}

\author{
Duk-Young Kang ${ }^{1 *}$, Hyo-Chan Kim ${ }^{1}$ and Young Jin Chang ${ }^{2}$ \\ ${ }^{1}$ West Sea Fisheries Research Institute, National Fisheries Research and \\ Development Institute, Incheon 400-420, Korea \\ ${ }^{2}$ Department of Marine Bio-materials and Aquaculture, Pukyong National University, \\ Busan 608-737, Korea
}

\begin{abstract}
To determine whether rearing density affects the hypermelanosis on the blind side (ambicoloration) of olive flounders Paralichthys olivaceus, we reared fry with an unpigmented non-eyed (blind) side in duplicate at densities of 150 individuals $/ \mathrm{m}^{2}$ (commercial production density: control) and 450 individuals $/ \mathrm{m}^{2}$ (high density group) for 90 days in $1 \mathrm{t}$ dark-green fiberglass reinforced plastics (FRP) tank. We recorded feed intake, feed conversion efficiency (FE), growth and survival, and measured the ratios of staining blind-side area (staining area) and ambicolored fish every 30 days. Daily feed intake (DFI), feed conversion efficiency (FE), growth rate, condition factors, and survival rate were calculated at the end of the experiment. Although the FE was higher in the high-density compared to the control, the two density groups showed similar feed intakes, growth, and survival. The ratio of staining area as well as the ratio of ambicolored fish significantly were significantly higher in the high-density group than in the control from days 30 to 60 , but significantly increased and evened out by the end of the experiment $(P<0.05)$. In conclusion, we determined that rearing density is not the main cause of the blind-side hypermelanosis, but found that increasing the rearing density can accelerate the ambicoloration in olive flounders.
\end{abstract}

Key words: Paralichthys olivaceus, Cultured flounder, Density, Blind side, Hypermelanosis, Ambicoloration

\section{Introduction}

Color changes in fish are generally divided into two types: temporary reversible changes and permanent irreversible changes, based on the time period and morphological characteristics involved. With reversible changes, skin colors can change depending on the situation and then return to their original color, whereas with irreversible changes, once the skin color changes, it never returns to the original. Centripetal and centrifugal movements of pigments in stellate chromatophores are believed to be the cause the former situation when the pigment cells complete their differentiation. This process is driven by many factors, including background pattern (Ramachandran et al., 1996), stress (Doolan et al., 2008), luminosity (Han et al., 2005), and nutrition (Kalinowski et al., 2005). The latter occurs when the

(c) This is an Open Access article distributed under the terms of the Creative Commons Attribution Non-Commercial License (http://creativecommons.org/licenses/by-nc/3.0/) which permits unrestricted non-commercial use, distribution, and reproduction in any medium, provided the original work is properly cited. number of chromatophores changes due to the differentiation of pigment cells, which is thought to be caused by inherited gene characteristics (Shikano, 2005; Jeong and Jeon, 2008; Kang and Lee, 2010), the existence of light (Iwata and Kikuchi, 1998), habitat conditions of habitats (Ottesen and Strand, 1996; Iwata and Kikuchi, 1998), the colors in surroundings (Amiya et al., 2005; Yamanome et al., 2005, 2007), and the stocking density (Takahashi, 1994).

In teleostes, high rearing densities are known to induce stress-induced temporary color changes (Doolan et al., 2008), bone deformation (Boglione et al., 2009), and smoltification (Hosfeld et al., 2009) and to affect growth (Bolasina et al., 2006; Merino et al., 2007), survival (Tagawa et al., 2004), sex ratio (Saillant et al., 2003), sexual maturation and spawning (Claudia et al., 2004), hatching (Peck and Holste, 2006), and cannibalism (Baras et al., 2003). However, whether density affects the differentiation and proliferation of pigment cells during the

\footnotetext{
*Corresponding author: dykang@hotmail.com

Copyright@The Korean Society of Fisheries and Aquatic Science
} 
development of flatfish such as the olive flounders remains unknown.

The hypermelanosis of the blind side (ambicoloration) in olive flounders Paralichthys olivaceus, which is included in the irreversible color change category and appears during seed production, is a principal concern in the production and release of flounder seedlings. While ambicoloration is uncommon in the wild, it is common in those farmed olive flounders that are mass produced in artificial culture facilities (Fig. 1). Ambicolored fish are sold at half to one-quarter of the price of the wild fish in commercial markets, causing economic losses to both the fishing and aquaculture industry. Skin pigment cells on the blind side of cultured flatfish continue to differentiate and manifest during growth (Kang et al., 2010). Given that most of the flounder seedlings released to increase coastal fish populations exhibit staining on the blind side, most flounders caught along the coastline have ambicoloration. If this trait is hereditary in respect of genetics or epigenetics, released ambicolored flounders could change the innate characteristics of wild flounders.

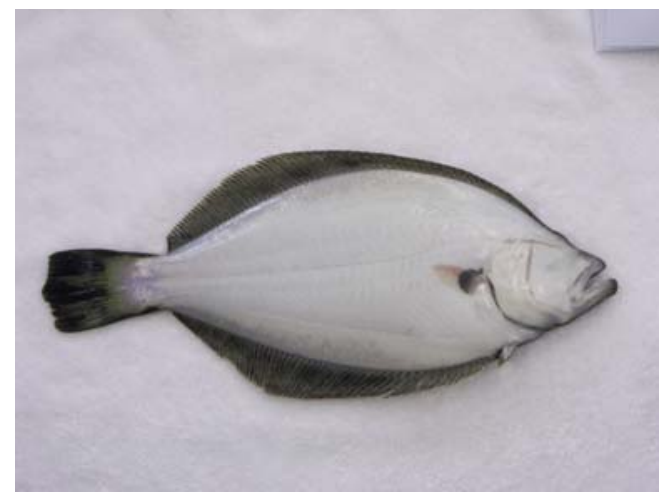

Typical type (wild flounder)

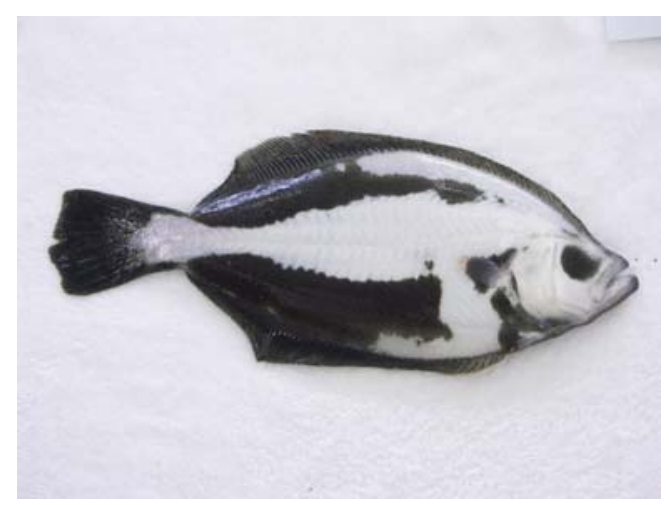

Ambicolored type (cultured flounder)

Fig. 1. Photographs of the blind side of wild and cultured olive flounders Paralichthys olivaceus.
Considering that wild adult and juvenile flounders are generally solitary, the stress of high rearing densities may induce the staining on the blind sides of artificially cultured fish. Bolasina et al., (2006) reported that fish do excessive stress when reared at high density in artificial facilities, and Takahashi (1994) identified a link between staining on the blind side and rearing density. However, several other studies have proposed factors other than rearing density as a cause for the malpigmentation (Ottesen and Strand, 1996; Iwata and Kikuchi, 1998; Haga et al., 2004; Amiya et al., 2005; Yamanome et al., 2005, 2007). Thus, whether density is the main driving factor is not clear. One must therefore determine whether rearing density is the main or secondary factor in ambicoloration. Here, we studied the relationship between rearing density as a stress-inducing agent and the blind-side hypermelanosis of olive flounders.

\section{Materials and Methods}

\section{Experimental fish}

The experimental 75-day-old fish were reared in grey $20 \mathrm{t}$ concrete tanks at the density of $200 \mathrm{fish} / \mathrm{m}^{2} / \mathrm{t}$ using flowing natural seawater (mean temperature $18.3 \pm 2.4^{\circ} \mathrm{C}$, salinity $30.7 \pm 0.4 \%$, and dissolved oxygen [DO] $7.1 \pm 0.5 \mathrm{mg} / \mathrm{L}$ ) with artificial lighting that simulated a natural photoperiod. To assess the effects of rearing density on the ambicoloration of olive flounders, 1,200 size-matched (total length [TL] $6.6 \pm 0.1 \mathrm{~cm}$, body weight [BW] $2.55 \pm 0.04 \mathrm{~g}$ ) fish not entirely stained on the blind side were selected and then divided in duplicate into two groups: at 150 animals $/ \mathrm{m}^{2}$ tank (commercial production density: control) and 450 animals $/ \mathrm{m}^{2}$ tank, respectively.

\section{Rearing performance}

The fish were transferred into a 1,000 L dark-green FRP tank (base surface area of $1 \mathrm{~m}^{2} /$ wall surface area of $1 \mathrm{~m}^{2}$ ) supplied with filtered seawater (one to fivefold water exchange rate per day depending on biomass) and reared with gentle aeration and artificial lighting simulating a natural photoperiod at a temperature of $19.7 \pm 3.2^{\circ} \mathrm{C}$, salinity of $30.9 \pm 0.3 \%$, pH of $7.7 \pm 0.3$ and $\mathrm{DO}$ of $7.3 \pm 0.8 \mathrm{mg} / \mathrm{L}$. The flow rates were identical in all tanks. Tank bottom were cleaned once a day by siphoning. With the exception of the sampling day, fry were fed twice daily to satiation with a commercial pellet diet (SCF, Incheon, Korea) (Table 1). The high-density rearing treatment was conducted for 90 days.

We recorded the mass of feed consumed by each group during the experiment, and determined the daily 
Table 1. Approximate composition of basal diet (\% of dry matter)

\begin{tabular}{lc}
\hline Component & Composition \\
\hline Protein & 50.0 \\
Lipid & 10.0 \\
Ash & 18.0 \\
Moisture & 7.5 \\
Crude cellulose & 2.0 \\
Potassium & 1.2 \\
Phosphate & 2.7 \\
Other mineral & 8.6 \\
\hline
\end{tabular}

feed intake (DFI=total mass of food/[days $\times$ fish], $\mathrm{mg} /$ fish/day) and the feed conversion efficiency (FE = body mass gain/mass of diet fed $\times 100, \%$ ). Daily mortality records were kept to calculate survival in each group. We measured the total length $(\mathrm{cm})$ and body mass (g) of each animal on the first and last day. The fish were not fed for $24 \mathrm{~h}$ prior to sampling, and they were anesthetized in $100 \mathrm{mg} / \mathrm{L}$ MS-222 buffered with $100 \mathrm{mg} / \mathrm{L}$ sodium bicarbonate. The daily growth rates in length (DGRL, $\%=\left[L_{f}-L_{i} / t_{2}-t_{1}\right] \times 10^{2}, t_{2}$ : final time, $t_{1}$ : initial time, $L_{f}$ : final total length, $L_{i}$ : initial total length) and mass (DGRM, $\%=\left[M_{f}-M_{i} / t_{2}-t_{1}\right] \times 10^{2}$, $M_{f}$ : final total mass, $M_{i}$ : initial total mass) and condition factor $\left(\mathrm{CF}=\right.$ final mass/(total length) $\left.{ }^{3} \times 10^{3}\right)$ were also calculated.

\section{Ratios of ambicolored fish and staining on the blind side}

To investigate the effects of rearing density on the abnormal pigmentation of the blind side of olive flounders, 30 flounders were collected in duplicate from each tank using a net ( $\mathrm{n}=60$ fish per group), at an interval of 30-90 days. For sampling, the fish were euthanized by 2-phenoxyethanol (1/1,000 dilution, $0.3-0.4 \mathrm{mg} / \mathrm{L}$ ), as an general anesthesia, and then were rinsed with distilled water to remove salt. Next, these samples were kept in $10 \%$ neutral formalin bottles. The blind sides of sampled flounders were photographed using a digital camera (DFC 320; Leica, Wetzlar, Germany) with a built-in stereomicroscope at the end of the experiment. Then, the ratio of the staining area $(\%=$ staining area of the blind side/total area of the blind side $\times 100$ ) between each group was analyzed on the final day using a micro-imaging analysis system (Qwin; Leica, Wetzlar, Germany) with the previously taken image. Individuals exhibiting staining of greater than $1 \%$ of the blind side area were considered to be ambicolored. The total number of ambicolored individuals was determined for each group and the ratio of ambicolored fish $(\%=$ ambicolored fish/total fish $\times 100)$ was calculated at 30 day intervals.

\section{Statistical analyses}

Statistical analyses were conducted to detect significant differences in the mean values between the two groups. DFI, FE, DGR, and survival rate were compared using the mean of two subsamples of 30 fish as replicates $(n=2)$, and TL, BW, CF, and the ratios of staining area and ambicolored fish were compared using the mean of 60 pooled sample individuals as replicates $(n=60)$. Using the statistics program SPSS version 7.0 (SPSS Inc., Chicago, IL, USA), a Mann-Whitney U-test in DFI, FE, DGR and survival, and $t$-test in TL, BW, CF were conducted with a significance probability of $95 \%$.

\section{Results}

\section{DFI, FE, growth, and survival}

Although DFI was not significantly different between the control and high-density groups, the DFI in the low-density setting (control) was a slightly higher than that in the high-density environment. Fish in the high-density group exhibited higher FE than those at low-density (Fig. 2). However, no significant difference was observed in the growth rate, $\mathrm{CF}$, or survival of fry between the two experimental groups (Table 2).

Table 2. Daily growth rate (DGRL and DGRM), condition factor (CF) and survival rate of juvenile olive flounder reared at two densities for 90 days

\begin{tabular}{lcccc}
\hline Treatment & $\begin{array}{c}\mathrm{DGRL}^{1} \\
(\%)\end{array}$ & $\begin{array}{c}\mathrm{DGRM}^{2} \\
(\%)\end{array}$ & $\begin{array}{c}\mathrm{CF}^{3} \\
\left(\mathrm{~g} / \mathrm{cm}^{3}\right)\end{array}$ & $\begin{array}{c}\text { Survival }^{4} \\
(\%)\end{array}$ \\
\hline 150 inds. $/ \mathrm{m}^{2}$ & $1.96 \pm 0.03$ & $28.9 \pm 0.5$ & $10.7 \pm 0.2$ & $86.4 \pm 4.1$ \\
450 inds. $/ \mathrm{m}^{2}$ & $1.98 \pm 0.02$ & $29.1 \pm 0.4$ & $10.6 \pm 0.1$ & $85.2 \pm 2.4$
\end{tabular}

${ }^{1}$ DGRL, daily growth rates in length; ${ }^{2}$ DGRM, daily growth rates in mass. Statistic was performed with Mann-Whitney U-test $(\mathrm{n}=2)^{1,2,4}$ and $t$-test $(\mathrm{n}=60)^{3}$ applied with a sig-nificance probability of $95 \%$ confidence level.

\section{Pigmentation on the blind side}

The changes in the ratios of staining area in the two groups throughout the testing periods are shown in Fig. 3. The ratios of staining area in both groups increased from zero to 90 days of growth and was significantly higher under high-density conditions from 30 to 60 days; however, the ratios were similar in the two groups by the end of the experiment period (Fig. 3).

In agreement with previous reports, the ratio of ambicolored fish was significantly higher in the high- 

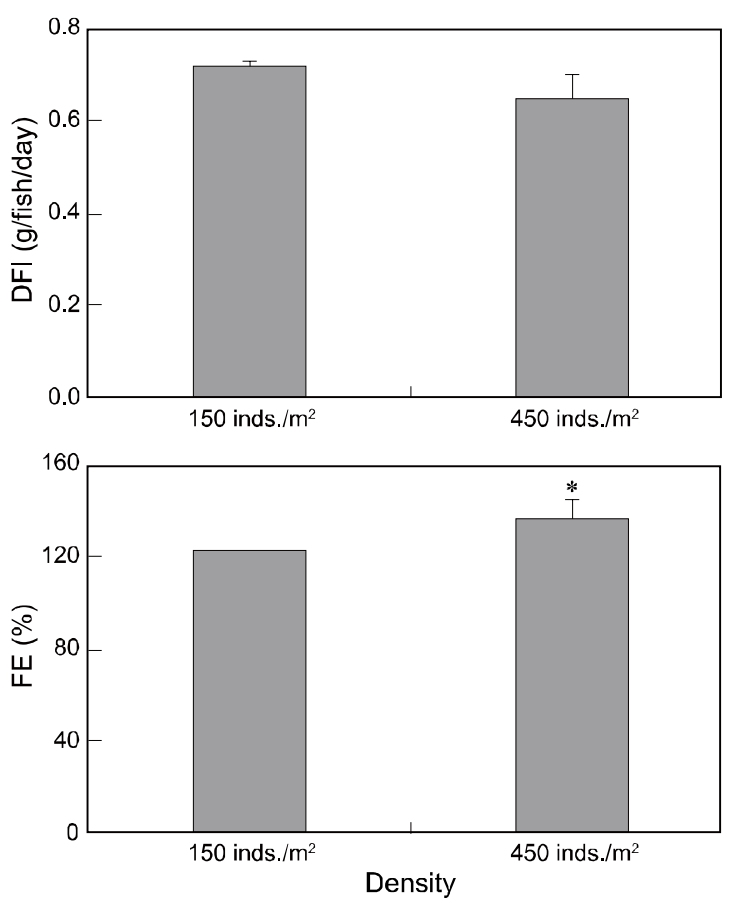

Fig. 2. Daily feed intake (DFI, g) and feed conversion efficiency (FE, \%) of juvenile olive flounder, Paralichthys olivaceus reared at two densities for 90 days. Variability is presented as mean \pm SE. Statistic was performed with Kruskall-Wallis test and MannWhitney U-test $t$-test applied with a significance probability of $95 \%$ confidence level $(n=2) . *$ indicates a significant difference $(P<0.05)$.

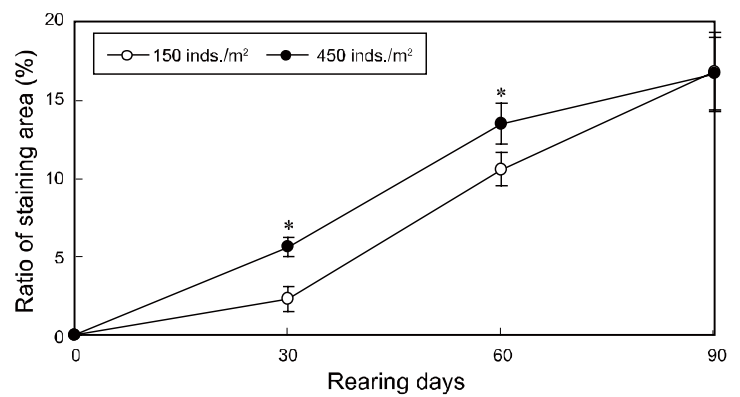

Fig. 3. Ratio (mean \pm SE) of staining area on the blind side of flounders, Paralichthys olivaceus reared at two densities for 90 days. Variability is presented as mean \pm SE. Statistic was performed with $t$-test applied with a significance probability of $95 \%$ confidence level $(\mathrm{n}=60)$. *indicates a significant difference $(P<0.05)$

density group from 30 to 60 days of growth, indicating that the pigmentation on the blind side occurred more quickly under high-density conditions $(P<0.05)$. However, the ratio in the both groups significantly increased and evened out by the end of the experiment (Figs. 4 and 5).

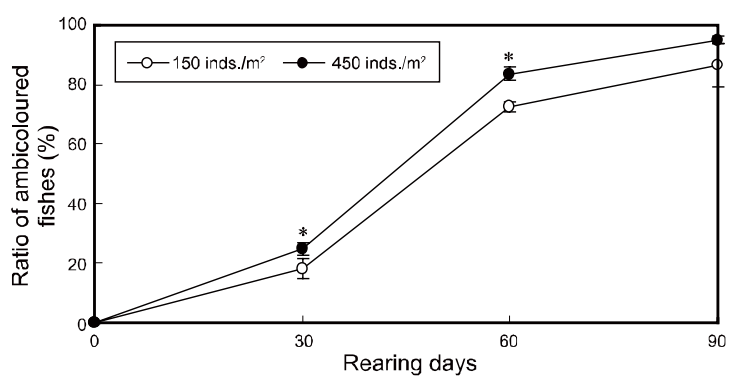

Fig. 4. Ratio (mean \pm SE) of ambicolored olive flounders, Paralichthys olivaceus reared at two densities for 90 days. Variability is presented as mean \pm SE. Statistic was performed with $t$-test applied with a significance probability of $95 \%$ confidence level $(\mathrm{n}=60) .{ }^{*}$ indicates a significant difference $(P<0.05)$.

\section{Discussion}

Our morphological observations showed that the blind-side malpigmentation as a result of differentiation and development of pigment cells (presumably melanophores, xanthophores and iridophores), which differentiate in the same way as on the ocular side, and as has been reported by Kang et al. (2010), is an irreversible change. The cause and mechanism of the hypermelanosis remain unclear, but are assumed to be a consequence of interactions between epigenetic (Kang and Lee, 2010) and environmental factors (Takahashi, 1994; Ottesen and Strand, 1996; Yamanome et al., 2005). Additionally, the factor that has the strongest impact on the irreversible pigmentation, and the mechanism involved in the development of this phenomenon that is so rarely seen in wild olive flounders remain unknown. Specifically, to determine the causes of abnormal pigmentation and to develop a mitigating technology, a physiological comparison of normal and abnormally staining fish is required to pinpoint stresscausing agents in farming. Therefore, based on Takahashi (1994), we studied the effects of rearing density as an environmental stress factor on blindside hypermelanosis in olive flounders.

Our results demonstrated that stock density does not ultimately influence the blind-side hypermelanosis of olive flounder. The staining area and ambicolored fish ratios in both groups increased significantly from $0 \%$ to more than $15 \%$ and $80 \%$, respectively, by the final day (90 days). However, given the present results, the rearing density can 


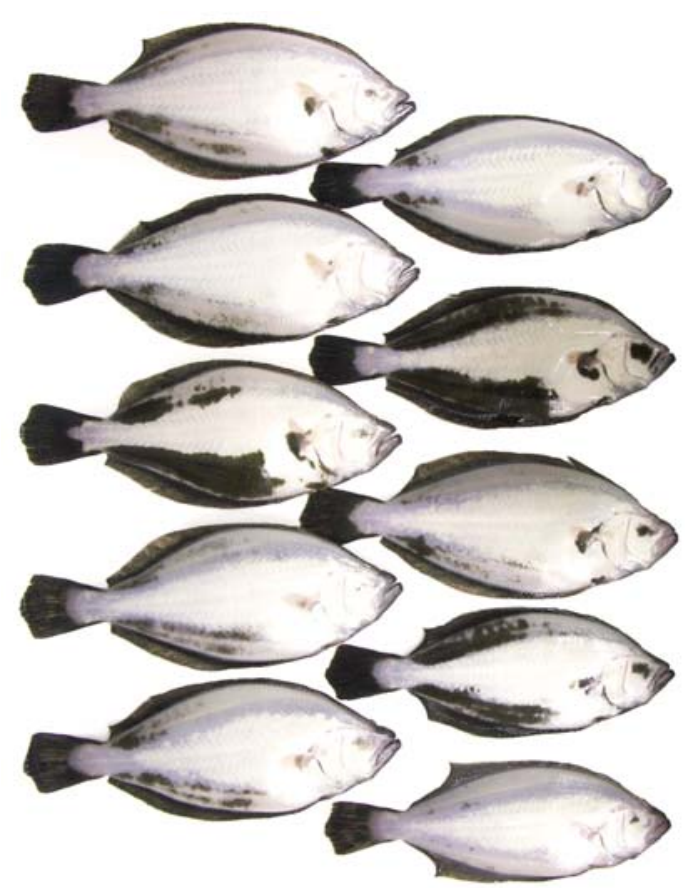

$150 \mathrm{fish} / \mathrm{m}^{2}$ (control)

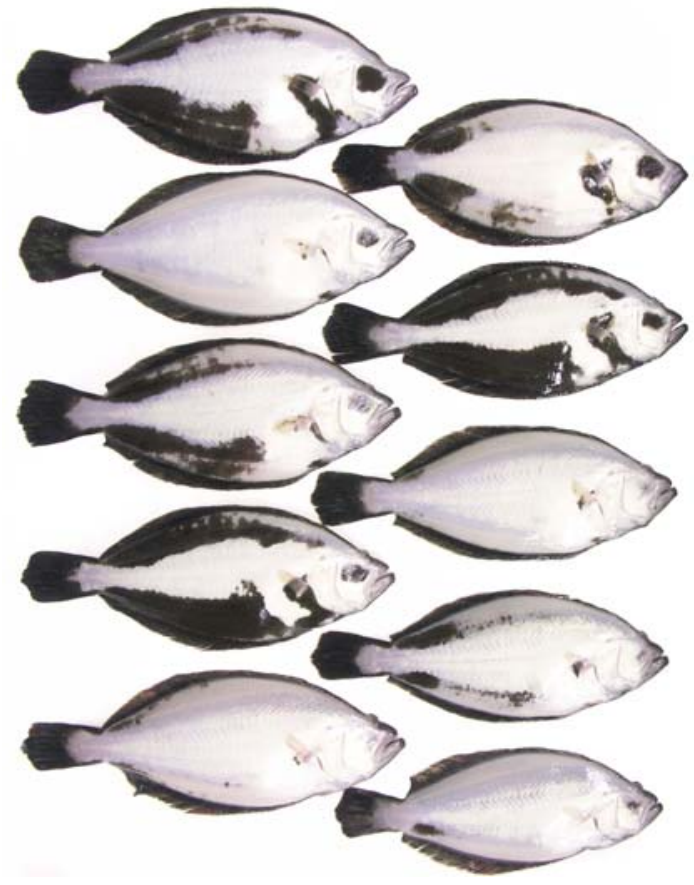

$450 \mathrm{fish} / \mathrm{m}^{2}$

Fig. 5. Photographs of the blind side of fry olive flounders Paralichthys olivaceus reared in two densities for 90 days.

account for a portion of the hypermelanosis, and can induce rapid progression of the symptom before 60 days of rearing. Although both groups showed similar feed intake, growth, and survival performances and the staining area ratio was equal between the groups by the end of the experiment, a high-rearing density does appear to increase the ratios of staining area and ambicolored fish from 0 to 60 days. These results indicate that high-density farming accelerates the bilateral body pigmentation of olive flounders, which is partially consistent with the results reported by Takahashi (1994), which suggested that abnormal pigmentation increases with stocking density. The apparent influence of density on the speed of malpigmentation on the blind side in flatfish may be due to a stress stimulus induced by increased crowding. Recently, Kim et al. (2008) found that ambicolored flounders exhibit higher stress levels than fish with normal coloring suggesting that abnormal pigmentation may be related to stress (Bolasina et al., 2006). Therefore, we propose that high-density farming conditions increase the stress levels of flounders, which in turn causes the growth of pigment cells on the blind side. This may represent a recurrence of cells that once served defensive camouflage purposes, which have since degenerated with evolution. However, note that the accelerating effect under high-density conditions was lost after 60 days. We suggest that this occurred because the total biomass per unit area in the low-density tanks increased as the fish grew, perhaps raising the density to a threshold at which these flounders experienced high-density stress levels. The effect of increased stress with time might also account for the delayed staining in the low-density group. This may have triggered the growth of the once-atrophied pigment cells on the blind sides of the fish, which it had reached the levels of the high-density group by day 90.

Here, we found that increased rearing density does not affect overall the blind-side staining, but accelerates the initial hypermelanosis of olive flounders. Our results suggest that crowding plays a role in the hypermelanosis of olive flounders, but that it is not the only environmental stress factor behind this phenomenon. Therefore, why ambicoloration only occurs under artificial rearing remain a mystery. Ambicoloration can be explained in two ways: as a morphological mutation by change of genomic sequence, or as a type of atavism in which ancestral traits reappear by silence phenotype and gene expression in genetics. We are in support of the latter opinion, proposed by Ivankova and Ivankov (2006) and Ivankov et al. (2008), because both partial and 
complete ambicoloration are clearly related to the evolution of flounders. Flounders (or Pleuronectiformes) are reported to have originated from ancestors close to either Zeiformes or Percopsiformes related to Percoidei (Ivankova and Ivankov, 2006; Ivankov et al., 2008). Recently, Friedman (2008) suggested flatfish evolved from symmetric fish, which lends credibility to the claim that flounders evolved from Zeiformes or Percopsiformes. We propose that pigment cells on the blind side, which had vanished during evolution, reappeared functionally by silence phenotype and gene expression under inadequate living conditions. Future studies of the possible relationships between epigenetic change and blindside pigmentation as an evolutionarily regressive trait are warranted.

In conclusion, although rearing density is not the main cause of the hypermelanosis on the blind side of olive flounders, an increased rearing density can accelerate the blind-side malpigmentation in olive flounders as was demonstrated by the number of ambicolored individuals and the area of the blind side. This is an important factor in this phenomenon that should not be overlooked.

\section{Acknowledgments}

The authors wish to acknowledge the financial support (F10600906A220000110/NFRDI RP-2010AQ-017) of the Ministry for Food, Agriculture, Forestry and Fisheries, Rep. of Korea made in the program year of 2006-2009.

\section{References}

Amiya N, Amano M, Takahashi A, Yamanome T, Kawauchi $\mathrm{H}$ and Yamamori K. 2005. Effects of tank color on melanin-concentrating hormone levels in the brain, pituitary gland, and plasma of the barfin flounder as revealed by a newly developed timeresolved fluoroimmunoassay. Gen Comp Endocrinol 143, 251-256.

Baras E, Kestemont P and Mélard C. 2003. Effect of stocking density on the dynamics of cannibalism in sibling larvae of Perca fluviatilis under controlled conditions. Aquaculture 219, 241-255.

Boglione C, Marino G, Giganti M, Longobardi A, De Marzi P and Cataudella S. 2009. Skeletal anomalies in dusky grouper Epinephelus marginatus (Lowe 1834) juveniles reared with different methodologies and larval densities. Aquaculture 291, 48-60.

Bolasina S, Tagawa M, Yamashita Y and Tanaka M. 2006. Effect of stocking density on growth, digestive enzyme activity and cortisol level in larvae and juveniles of Japanese flounder, Paralichthys olivaceus. Aquaculture 259, 432-443.

Claudia CO, Miguel RS, Angel ONM and GutiérrezYurrita PJ. 2004. Effect of density and sex ratio on gonad development and spawning in the crayfish Procambarus llamasi. Aquaculture 236, 331-339.

Doolan BJ, Allan GL, Booth MA and Jones PL. 2008. Effects of cage netting colour and density on the skin pigmentation and stress response of Australian snapper Pagrus auratus (Bloch \& Schneider, 1801). Aquac Res 39, 1360-1368.

Friedman M. 2008. The evolutionary origin of flatfish asymmetry. Nature 454, 209-212.

Haga Y, Takeuchi T, Murayama Y, Ohta K and Fukunaga T. 2004. Vitamin $D_{3}$ compounds induce hypermelanosis on the blind side and vertebral deformity in juvenile Japanese flounder Paralichthys olivaceus. Fish Sci 70, 59-67.

Han D, Xie S, Lei W, Zhu X and Yang Y. 2005. Effect of light intensity on growth, survival and skin color of juvenile Chinese longsnout catfish (Leiocassis longirostris Günther). Aquaculture 248, 299-306.

Hosfeld CD, Hammer J, Handeland SO, Fivelstad S and Stefansson SO. 2009. Effects of fish density on growth and smoltification in intensive production of Atlantic salmon (Salmo salar L.). Aquaculture 294, 236-241.

Ivankova ZG and Ivankov VN. 2006. Specific features of the external morphology of starry flounder Platichthys stellatus at atavism in the body color. J Ichthyol 46, 436-440.

Ivankov VN, Ivankova ZG and Vinnikov KA. 2008. Reversal of sides in the blackfin flounder Glyptocephalus stelleri and variability of body pigmentation and shape in pleuronectid flatfishes. Russ J Mar Biol 34, 254-257.

Iwata N and Kikuchi K. 1998. Effects of sandy substrate and light on hypermelanosis of the blind side in cultured Japanese flounder Paralichthys olivaceus. Environ Biol Fishes 52, 291-297.

Jeong DS and Jeon CY. 2008. Genetic variability and population structure of olive flounder Paralichthys olivaceus from stocked areas using microsatellite DNA markers. Korean J Ichthyol 20, 156-162.

Kalinowski CT, Robaina LE, Fernández-Palacios $H$, Schuchardt D and Izquierdo MS. 2005. Effect of different carotenoid sources and their dietary levels on red porgy (Pagrus pagrus) growth and skin colour. Aquaculture 244, 223-231.

Kang, DY and Lee JW. 2010. Study of the causes of malpigmentation and development of pigmentation control technology in cultured olive flounder. In: 
Report of Fisheries Research Project, Seoul, KR, pp. 97-98.

Kang DY, Kim HC and Chang YJ. 2010. Changes of abnormal pigmentation on blind side of cultured flounder, Paralichthys olivaceus with growth. In: Proceeding of the Ichthyological Society of Korea 2010. Ichthyological Society of Korea, Seoul, KR, p. 63.

Kim HC, Kang DY, Cho KC, Kim KH, Myeong JI and Kang HW. 2008. Possible endocrinal relevance of $\mathrm{MCH}$, cortisol and thyroid hormones to hypermelanosis of olive flounders, Paralichthys olivaceus reared in culture system. In: Proceeding of 6th International Symposium of Fish Endocrinology. Calgary, AB, CA, p. 16.

Merino GE, Piedrahita RH and Conklin DE. 2007. The effect of fish stocking density on the growth of California halibut (Paralichthys californicus) juveniles. Aquaculture 265, 176-186.

Ottesen OH and Strand HK. 1996. Growth, development, and skin abnormalities of halibut (Hippoglossus hippoglossus L.) juveniles kept on different bottom substrates. Aquaculture 146, 17-25.

Peck MA and Holste L. 2006. Effects of salinity, photoperiod and adult stocking density on egg production and egg hatching success in Acartia tonsa (Calanoida: Copepoda): optimizing intensive cultures. Aquaculture 255, 341-350.

Ramachandran VS, Tyler CW, Gregory RL, RogersRamachandran D, Duensing S, Pillsbury C and
Ramachandran C. 1996. Rapid adaptive camouflage in tropical flounders. Nature 379, 815-818.

Saillant E, Fostier A, Haffray P, Menu B, Laureau S, Thimonier J and Chatain B. 2003. Effects of rearing density, size grading and parental factors on sex ratios of the sea bass (Dicentrarchus labrax L.) in intensive aquaculture. Aquaculture 221, 183-206.

Shikano T. 2005. Marker-based estimation of heritability for body color variation in Japanese flounder Paralichthys olivaceus. Aquaculture 249, 95-105.

Tagawa M, Kaji T, Kinoshita M and Tanaka M. 2004. Effect of stocking density and addition of proteins on larval survival in Japanese flounder, Paralichthys olivaceus. Aquaculture 230, 517-525.

Takahashi Y. 1994. Influence of stocking density and food at late phase of larval period on hypermelanosis on the blind body side in juvenile Japanese flounder. Nippon Suisan Gakkaishi 60, 593-598.

Yamanome T, Amano M and Takahashi A. 2005. White background reduces the occurrence of staining, activates melanin-concentrating hormone and promotes somatic growth in barfin flounder. Aquaculture 244, 323-329.

Yamanome T, Amano M, Amiya N and Takahashi A. 2007. Hypermelanosis on the blind side of Japanese flounder Paralichthys olivaceus is diminished by rearing in a white tank. Fish Sci 73, 466-468.

(Received 8 March 2011; Revised 14 April 2011; Accepted 16 May 2011) 